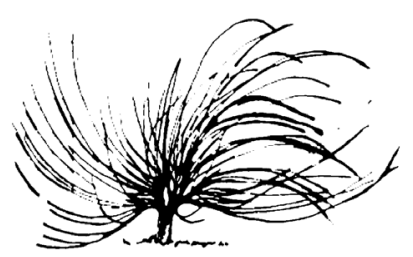

\title{
Educación insumisa ante el pensamiento único: ¿Quién te vigila?
}

\author{
Carlos Esteban Hernández Navarro ${ }^{1}$ \\ Universidad Nacional \\ Costa Rica \\ carloshernandezn1990@gmail.com
}

Sofia Cruz Icabalceta ${ }^{2}$

Universidad Nacional

Costa Rica

sophiale.cruz@hotmail.com

$$
\begin{array}{r}
\text { Luis Miguel Rodríguez Soto } \\
\text { Universidad Nacional } \\
\text { Costa Rica } \\
\text { luikro13@gmail.com }
\end{array}
$$

"Por falta de comprensión, todos eran politicamente sanos y felices"

(Orwell, 1948, p. 75).

"El espiritu puro es una pura estupidez".

(Nietzsche, 2000).

Para introducir: el grito por la autonomía frente a la muerte de la libertad

En el presente texto, con base en la novela escrita por George Orwell titulada 1984 publicada en 1948, serán analizados ciertos aspectos que, al ser pensados en el contexto pedagógico, podrían permitir 
el esbozo de algunos criterios que contribuyan a la comprensión de la necesidad, en nuestra actualidad, de proponer una práctica educativa para la vida, a modo de conciencia política. Se persigue el objetivo de dar sustento a la emancipación humana, en la lucha ante un sistema violento que se reproduce desde la institucionalidad educativa, que resulta, por su actuar y selección de técnicas, represivo y opresor.

Partiendo de la proyección del futuro, plasmada en la novela, en relación con el presente continuo, se vislumbra la denuncia de los regímenes de poder político e institucionalizado en nuestra actualidad y realidad que se vivencia en las aulas. Es importante señalar que este documento es fruto de consultas bibliográficas, reflexiones entre los escritores del presente ensayo y diálogos grupales realizados con distintos estudiantes de secundaria, se coincide en que la influencia institucional marca significativamente el pensamiento de las personas que hemos pasado por ellas, y también la naturalización que hemos aceptado, sin más de la imposición que realiza en sus ideales sobre el estudiantado.

Si bien, sabemos que la semejanza entre ambos mundos (la novela y el presente) no es idéntica, podemos percibir técnicas relevantes que han propiciado la escolarización, entendida como una propuesta autoritaria en su sentido moderno, caracterizada por un desenfrenado deseo de control social y poder político. De tal modo, nos interesa escudriñar sobre el cómo se ha llevado a cabo la utilización de tecnologías para el mantenimiento de ese orden moderno, dado que en la novela se presenta bajo las consigna del "Gran hermano" la idea de un control omnipresente, y que hoy en día podría vincularse con la obsesiva práctica de observarlo todo, mediante cámaras de "seguridad" presentes en todos los rincones de la ciudad, de los pasillos de las instituciones, y en especial de las educativas, con el único fin de eliminar la privacidad y naturalizar el control; excusándose de ser una herramienta de cuido para las personas y sus objetos materiales. ¿De quién debería cuidarse el estudiantado dentro del centro educativo? O mejor aún, ¿quién vigila al vigilante?

Quien ejerce el rol de vigilar es quien tiene el poder para hacerlo. Nos preguntamos: ¿quién y cómo adjudica el poder a alguien de vigilar a las demás personas, en este caso a alumnos y alumnas? ¿Y cuáles son las posibles reacciones de las personas al sentirse vigiladas por un ente sin rostro que se hace llamar a sí mismo "justicia"? 
Si seguimos la línea de la obra literaria aquí expuesta, encontramos que el miedo es una respuesta. El miedo doblega, a tal punto que invisibiliza los actos represivos. La culpa del oprimido resulta del miedo que produce la falsa idea de estar de acuerdo con el acto del opresor (Freire, 1970), por lo que nos surgen las interrogantes: ¿El aprendizaje se da por deseo, necesidad, motivación o intención de quien aprende? ¿O simplemente se impone de forma sigilosa por medio de intereses políticos que manipulan los medios de comunicación, currículos, y además dictan el deseo, necesidad, motivación e intención de quienes quieren aprender? (Torres, 1998).

Justificamos esta reflexión desde el robo (lo llamamos robo porque en ningún momento se les da el espacio para mostrarse tal y como se perciben) de la autonomía y la identidad de los y las jóvenes a causa de la vigilancia y el control impuesto institucionalmente, que regula las normas de conducta dentro de las instituciones, lo cual imposibilita identificar su subjetividad o individualidad, descomponiendo la creatividad y elaborando en cambio máquinas humanas que dejan de hacer por gusto o necesidad y hacen por obligación y sin afinidad.

Esta obra literaria de George Orwell nos muestra un mundo sumiso cuya población, en su mayoría, desertó a la resistencia de sus opresores; aceptando sin reflexionar lo que se les dice desde la fuerza del Estado Moderno, maquinaria opresora por excelencia, que mediante la idea imaginaria de un contrato social se jacta de un poder totalitario disimulado a través de procesos llamados democráticos. Pero, como en 1984, la manera en la que se ejerce el poder se basa más en los conflictos armados y los privilegios jerárquicos que en las decisiones o participación ciudadana, que, además, como lo dijimos anteriormente, son manipuladas por las herramientas de poder desde el sistema educativo.

\section{EI (neo)lenguaje como una pedagogía idiotizante}

Entre las herramientas de poder ejercidas en la obra encontramos la "neolengua", que es utilizada como representación de la capacidad que tiene el lenguaje para modificar y controlar las vidas, pensamientos e ideologías de las personas, lo que podría expresarse en el siguiente lema: "lo que no se dice no existe", que, desde nuestra interpretación, expresa una práctica de invisibilización del oprimido, hecho cotidianizado en las actuales sociedades modernas. La "neolengua" se define desde el mismo 
libro como "la lengua oficial de Oceanía y fue creada para solucionar las necesidades ideológicas del Ingsoc o Socialismo Inglés" (Orwell, 1970, p. 293). Hay en esta cita mucho que puede ser analizado críticamente en función de la pedagogía. Primero, hay que tomar en cuenta que el lenguaje es el medio por excelencia por el cual se transmite el conocimiento $\mathrm{y}$, al mismo tiempo, es la forma individual de reconocer nuestra realidad, nombrándola. Segundo, incluso es la herramienta del ser humano más utilizada para darle sentido y significado a las realidades que afronta e implica un nacer de cada cultura. Con esto queremos exponer que si se reducen las palabras, como se hizo en la obra, se reducen las posibilidades de darle sentido a las realidades, y aún peor, se aumenta el poder que impone la hegemonía, enfocado a la disminución de las posibilidades para comprender y transformar la realidad.

Al decir que era la lengua oficial y que fue creada por ellos (la institución política), es importante recalcar que fue el poder hegemónico quien le dio sentido y significado a la realidad que se quería universalizar. El poder hegemónico negó la posibilidad de nombrar lo que se manifestaba como opuesto a su ideología, esto nos lleva a la pregunta: ¿al no poder nombrarlo, puede pensarse la resistencia? La novela nos dice que sí es posible mediante sus dos personajes principales, y es este el impulso para los actos emancipatorios. Ahora bien ¿cómo llevar esto a las aulas? ¿Cómo dar a los y las estudiantes las herramientas para que puedan ejercer sus pensamientos libremente, aunque vayan en contra de los intereses institucionales?

$\mathrm{Si}$ pensamos el neolenguaje contemplando sus características represivas dentro de las instituciones de educación, donde los y las docentes son quienes imparten los conceptos que se asumen como necesarios para entender el mundo y para dar sentido a la vida académica en secundaria, queda evidenciado que se les niega a los y las estudiantes pensar más allá de aquello a lo que dichos conceptos académicos remiten, legitimando a su vez la verticalidad pedagógica entre ambos sujetos educativos. Aun así, ¿Puede el estudiantado crear/construir sus propios conceptos? Por supuesto que sí, pues debido a la calidad de indeterminación propia del ser humano es imposible reducirlo a la obediencia mecánica por más que se pretenda tan espuria tarea (Giroux, 1992). Sin embargo, lo que dificulta que se dé este proceso de autonomía es la figura omnipresente y academicista de la autoridad reguladora que establece lo que se puede o no decir en los centros de estudios. La 
propuesta es, entonces, crear e implementar didácticas o investigaciones que permitan en su desarrollo la formación de sujetos-aprendices pensantes que verbalicen, desde sus perspectivas y contextos cotidianos ( $\sin$ negar el valor de los conceptos plasmados con anterioridad pero brindando espacios de reflexión sobre los mismos, dando potestad a los y las estudiantes para decidir su validez), al brindar herramientas que permitan justificar por qué el desacuerdo con lo impuesto y también sus alternativas y propuestas.

Siendo así, ¿las instituciones educativas deberían permitir al estudiantado crear su propio lenguaje? Lo anterior, en tanto entendamos el lenguaje como una herramienta humana para construir el conocimiento.

\section{Realidad y ficción, más allá de la novela}

Las relaciones de poder sobre el plano institucional, estatal y social que comprendemos en nuestra realidad, más allá de ser solo un ejemplo, podrían ser prueba contundente de que no nos encontramos muy lejos de la ficción que se nos presenta en la novela 1984, de George Orwell, escrita entre los años de 1947 y 1948.

De manera que, para poder iniciar este recuento de situaciones, primero deberíamos verificar realmente nuestra presencia o no en el siguiente acontecimiento. Por orden y número, vamos a disponer de listas y registros para dar inicio al proceso de control para el aprendizaje. Por otra parte, para el orden estatal, el número de cédula representa una forma de identificación dentro de aquel monstruoso organismo; modos para el registro y el control de las personas en un sistema que reduce a los sujetos a números y cualidades cuantificativas. En ese orden de cosas, como apunta Illich (1977), la titulación se convierte en un modo de degradación humana oficializada, pues "la escuela que ayudó en el siglo pasado a superar el feudalismo, se está convirtiendo en ídolo opresor que solo protege a los escolarizados. Ella gradúa y, consecuentemente, degrada. Por fuerza del mismo proceso, el degradado deberá volver a sometérsele" (p. 86).

Pero el control solo empieza ahí. Podemos extendernos a pensar, desde el ámbito institucional, cómo también se impone a manera de requisito y necesidad, portar impecable el uniforme correspondido por las convenciones. La apariencia es un aspecto clave para el juego de las impresiones. Podríamos ante esto pensar, a la vez, cómo la perspectiva 
estética de igual forma cae en restricciones y regulaciones dentro del entorno institucional. Esto en la obra 1984 se refleja en la descripción que se ofrece del contexto gris e incoloro; claro, a excepción de los carteles y panfletos de propaganda del partido. De forma similar, para nuestra realidad, situarse en una ciudad resulta muy curioso: es adentrarse en una marea gris en donde solo resaltan pautas publicitarias que pretenden dictar nuestros propios deseos; aunque también la industria mediática masiva toma partida en este juego, con su fábrica de ilusiones, de reflejos y formas objetivas.

Ahora, siguiendo la obra de G. Orwell, es de nuestro interés recalcar las nociones reiteradas de control y vigilancia, de crimen y castigo que se presentan en la obra; cuestión que para la autora y autores de este ensayo no se aleja de nuestra realidad social y el entorno educativo, en donde el temor también está presente y se transforma en una estrategia política de control cotidiana que hemos naturalizado "en favor" de nuestra seguridad.

Para aquellos y aquellas a quienes vigila la "policía del pensamiento" en la obra, y el rol de la fuerza pública y los funcionarios policiales en la realidad, no es posible escapar de la óptica del juicio y el prejuicio. No solo observando se controla, existe hoy en día -en nuestras sociedades de la información- la tecnología suficiente para emitir ondas de sonido, las que pueden ser y son captadas y grabadas. En la novela en cuestión se utilizan telepantallas que todo lo ven, mientras que, en nuestra cotidianidad, incluso en algunos centros educativos como ya se apuntó, existe una inmensa cantidad de cámaras u ojos vigías que dan la idea del panóptico de Bentham.

Para el ambiente del aula, esta pretenciosa función policial la ejerce, o se pretende que la ejerza, el o la docente acuerpados por miembros administrativos y administrativos docentes de la institución, así como de los reglamentos internos que lo propician. Bajo el cargo funcional del docente policía (Illich, Gintis, Greer, Postman, Gross y Fairfield, 1977), se otorga la potestad de controlar y registrar lo acontecido para la corrección, rectificación, el castigo, la detención, la reducción de puntos o la boleta que intenta persuadir al estudiante de no desobedecer a la autoridad. ¿Pero con qué potestad la institución se jacta de tan suntuosa añoranza, clara correspondencia de una producción magistral, a saber, la reproducción de su sistema? 
En esta maraña ideológica, no solo el Estado y las instituciones dictan sobre la forma de pensar y ser, de hacer y desear; también, como ya mencionamos anteriormente, los medios de comunicación juegan un papel importante para la transmisión y propagación del orden establecido, del pensamiento normalizado. En la obra de Orwell, por ejemplo, se utilizaban carteles, canciones, slogans y masivos espectáculos; ya sea por medio de imágenes y sonidos, con la intención de manipular las emociones y la voluntad de los y las partidarias de Oceanía. En nuestra sociedad actual, por otra parte, esta estrategia mediática funciona, y en una medida más intensa y masiva: la propaganda, ya no solo política, también es asumida por las empresas productoras de mentalidades consumidoras. Los noticiarios, que lo que menos hacen actualmente es informar, promueven miedo y terror para justificar las prácticas autoritarias del mismo gobierno.

Ante esto, resulta necesario mencionar que las patentes para optar por un medio para la difusión televisiva o radial, están acaparadas por empresas que -no es de extrañar- están ligadas con intenciones ético-políticas controladoras y de reproducción acumulativa del capital en pocas manos; por otra parte, es curioso señalar que la información que se transmite en dichos medios de (des)información, primero tiene que pasar por un control de calidad para considerar si es apta o no para ser transmitida. ¿Afecta esto al estudiantado? Pareciera claro que les afecta en la medida en que la sociedad pretenda controlarlos o quiera que les afecte; ya sea desde música denigrante, películas violentas, nuevas drogas, redes sociales con contenidos sexuales humillantes, y a partir de un sin fin de productos que promueven la idea de que la felicidad se puede comprar o alcanzar sin mayor erogación ética. Así la felicidad se convierte en un producto más del morbo social establecido o impuesto.

Es interesante analizar, desde la obra, cómo utilizan los himnos y los cantos para la reproducción ideológica; dice Wiston, es "un modo deliberado de ahogar la conciencia mediante un ruido rítmico" (autohipnosis), (Orwell, 1970, p. 9). Ahora bien, podríamos plasmar eso mismo desde nuestra realidad, y decir que los himnos y cantos que glorifican a la patria no se alejan de ser mecanismos para la manipulación y la extorsión ideológica. Desde la escuela hasta el colegio y la universidad, los y las alumnas deben, por respeto y obligación, doblegarse ante una bandera, representar a la institución en desfiles, actos cívicos y demás prácticas que pretenden estimular esa obligatoriedad para con el páter institucional. 
¿Pero qué sucede si se desobedece a la autoridad totalitaria? Desde la óptica de la obra, es considerado como una falta del sentir natural para con el partido; en otras palabras, es un crimen mental, es decir, un denominado "crimental". ¿Y para la realidad actual? ¿Cuáles serían las repercusiones de no estar de acuerdo con la ideología establecida? La principal finalidad del entramado ideológico es la obediencia sin más, la repetición de lo establecido sin cuestionar sus fundamentos (Cerletti, 2016), en el que se subsume la institución, la educación, la tecnología y los medios de comunicación. Para que lo anterior suceda, a pesar del espíritu de indeterminación humana, es que precisamente se da el uso y abuso del control y el poder, de ideología de la modernidad, la justificación del consumismo opulento, la verticalidad pedagógica, las normativas institucionales en el aprendizaje...

Pero si continuamos con el análisis entre la obra 1984 y la realidad, otra noción interesante que emerge es la cuestión sobre la historia; ya que la misma, en el texto, se modifica y reedita a medida que la situación del momento lo amerite; en otras palabras, la historia es ahistórica en un sentido semántico. Así volvemos a la cuestión sobre cómo se manipulan las personas, desde la memoria y el pasado, hasta el presente y lo futuro. En la novela de Orwell, hay un lema interesante que promueve el partido, y es el siguiente: "quien controla el pasado controla el futuro, quien controla el presente controla el pasado" (Orwell, 1970, p. 18). De modo tal, que recordar es peligroso y tener una utopía para el futuro es desacertado por improcedente, así solo se permite el presentismo como acción constante e inconsciente de la obediencia institucionalizada.

Para imponer el control y el ordenamiento, la educación adoctrinadora, la tecnología y los medios de comunicación son vías para efectuar el enclave ideológico; para naturalizar normas y principios que sostienen al partido en la obra, y al Estado en nuestra realidad. En la citada obra de Orwell, por ejemplo, los principios de los que se vale el partido del Gran hermano para validar la jerarquía y el poder son la neolengua, el doblepensar y la mutabilidad del pasado. Del primero podríamos mencionar que son estrategias para degenerar la realidad objetiva, limitantes para el pensamiento, fórmulas para reducir los conceptos a unos cuantos aceptados; por su parte, el doblepensar se realiza por medio de la manipulación de las personas en su identidad, lo que conlleva a contradicciones y absurdos de hechos y conceptos que son aceptados con naturalidad; por último, la variabilidad del pasado, como 
ya vimos, consiste en suprimir hechos, controlar la historia a disposición y en función de las intenciones del partido en el presente.

Otro punto clave en la obra para la conservación del statu quo por parte del partido de Oceanía, es el constante estímulo a la prostitución, el juego, el fútbol, la cerveza, la lotería, los robos y las drogas entre las proles; así, las descendencias carecen de sentimiento político, y solo se quejan de cosas insignificantes, cuestiones que realmente no llegan a tener importancia para la política del partido.

Pero en la obra, Winston, nuestro personaje principal, no soportó más tal embate social, y ante el desencanto y siguiendo su rebeldía, decide iniciar con un diario, máxima representación identitaria de la conciencia libre. Aunque claro, esto significaba un serio crimental, pero para él era su mayor apuesta. Winston consideraba que el pasado suprimido aún sobrevive, que se mantiene en algunos objetos sólidos y sin etiquetas que los distingan; y que la historia, para el partido, existe solo como un interminable presente. Ante esto, considera el personaje, es necesario generar dudas por medio de pruebas, crear centros de resistencia, grupos de descontento que dejen su testimonio para las próximas generaciones.

Otra noción interesante por considerar en la novela es el sentido que se le otorga al acto sexual, ya que estaba desentendido del placer. La educación sexual se preveía para formar personas castas, puras, sin sentimientos; por otra parte, el matrimonio se disponía desde un deber con el partido de engendrar futuro/as partidarios/as de la ideología de Oceanía. El puritanismo sexual del partido se basaba en la represión del instinto, en evitar el placer; esto para crear un estado de histeria y así dar paso a una adoración y una fiebre guerrera para su provecho. Ante esto, Winston y Julia engendraron un amor puro, como acto político de resistencia, en donde los abrazos eran las batallas, y el clímax su victoria final; era una liberación al placer, en donde juntos construyeron un mundo secreto para vivir a gusto, felices, en una transición del deseo al afecto y la honda ternura. La habitación en donde ambos se encontraban, resultó ser todo un mundo completo, en donde la vida dejaba de ser insoportable.

La perspectiva de Julia, otro personaje central de la trama difería un tanto de la de Winston. Para ella, la realidad fuera de la habitación estaba consumada por el partido: todo era puro fatalismo, imposible de modificar. Según su visión, lo mejor era gritar siempre con el partido, seguir sus consignas, a modo de estar seguros (doblepensar). También, 
Julia consideraba que la guerra no existía, que era una mera invención del partido para que en la gente percibiera miedo, odio y adulación. Ese fatalismo, que se normaliza como regla no solo es un asunto de la novela orweliana, es sin duda, una pretensión del modelo capitalista-moderno que desde su matriz sexista, racista y clasista nos dice que más allá de sí mismo no existe otra posibilidad, e incluso se atrevió a declarar el fin de la historia luego de la caída del Muro de Berlin y de la desaparición de la Unión Soviética.

El manejo de la opinión pública, en la obra y en la realidad, se da en función de forzar la obediencia a la voluntad del Estado y crear uniformidad de opinión; estos son procesos presentados como actos de colectivización para mantener la moral. "Todo se reduce a un problema de educación, a moldear continuamente la mentalidad del grupo dirigente y del que se halla inmediatamente debajo de él" (Orwell, 1970, p. 100).

De esta forma, el Gran Hermano es la concreción con la que el partido se presenta al mundo, desde la clase que representa al partido interior, la clase del partido exterior, y la clase de vencedores siempre vencidos que resulta ser la prole. Así se efectúa, por medio de las costumbres, las aficiones, las emociones y las actitudes, la mística del partido; la estructura jerárquica donde la desigualdad social es aceptada sin crítica alguna, tal cual sucede en nuestra sociedad moderna cuando la educación nos adoctrina y no nos libera de dicha opresión pretendida.

Ante estas nociones, es necesario comprender los mecanismos (el cómo) y los motivos ocultos de toda sociedad (el para qué y el por qué), poseer conciencia del telos de la educación dentro del entorno social, si vela en función de imposiciones para crear autómatas, o, por otra parte, se propone motivar y crear personas no repetidoras sino críticas, transformadoras y que den sentido a sus vidas y a las de los demás. Pero en la novela, y lamentablemente en nuestra realidad, el poder es visto como un fin en sí mismo, una forma de obtener el bienestar de la minoría por la felicidad antes que la libertad, ya que las masas prefieren la primera por la cobardía y la debilidad, por eso la protección del partido.

\section{En conclusión}

Podríamos retomar algunas de las cuestiones vistas; por ejemplo, el lenguaje, pues su reducción implica la limitación del conocimiento, esta es una contradicción que debe ser valorada para replantear la 
mediación del lenguaje en las aulas, puesto que quien habla no es siempre el que tiene razón, sino a quien el poder se lo permite.

En este punto, podemos referirnos a la relación educador-educando y educando-educador, como una doble vía para la formulación de un tipo de diálogo en el que ambas partes se afirman y se educan en el proceso, en reciprocidad; una especie de inter-retroalimentación continua. Así mismo, claro está que, como una necesidad, debemos dilucidar las relaciones de poder dentro del ámbito educativo y social; decodificar y analizar, subjetiva y culturalmente, las prácticas e ideas que estimulan el dominio sobre los demás.

Tampoco es recomendable descuidar el ambiente y entorno en el que se desarrollan los procesos de enseñanza y aprendizaje, llámese país, ciudad, colegio o aula. En la novela se nos presenta esa realidad como algo fundamental para el dominio ideológico de los oprimidos, situación que en el presente se nos muestra cada vez con más fuerza mediante la imposición del pretendido pensamiento único del neoliberalismo moderno.

A todo esto, proponemos un repensar social, ético-político de la pedagogía ejercida desde el sistema educativo, en el cual la inclusión sea la respuesta a la imposición, la diversidad responda ante la xenofobia, discriminación, racismo epistémico, patriarcado y patria, como alternativa para la gestación de aprendizajes significativos, críticos y transformadores que se enfrenten al individualismo intelectual, en donde se reivindique el rol del/la docente como un sujeto mediador en un espacio en miras a construir una horizontalidad conjunto a los y las estudiantes en los diversos procesos que permean la enseñanza- aprendizaje, dejándose de lado la obsesión moderna de explicarlo todo para imponer suavemente doctrinas deshumanizantes (Rancière, 2008).

\section{Referencias}

Cerletti, A. (2016). La enseñanza de la filosofia en perspectiva. Buenos Aires: Eudeba.

Freire, P. (1970). Pedagogía del oprimido. Buenos Aires: Siglo XXI.

Giroux, H. A. (1992). Teoría y resistencia en educación: una pedagogía para la oposición. Buenos Aires: Siglo XXI.

Illich, I. (1977). Alternativas. México: Editorial Joaquín Mortiz. 
Illich, I., Gintis, H., Greer, C., Postman, N., Gross, R., y Fairfield, R. P. (1977). Un mundo sin escuelas. México: Nueva Imagen.

Nietzsche, F. W. (2000). Sobre la utilidad y los perjuicios de la historia para la vida (Vol. 249). España: Edaf.

Orwell, G. (1970). 1984. España: Salvat editores.

Rancière, J. (2008). El maestro ignorante. España: Mimesis.

Torres, J. (1998). El currículum oculto. España: Ediciones Morata. 